\title{
Estimation the influence of vitamin-mineral complex on reproductive characteristics of sterlet (Acipenser ruthenus L.)
}

\author{
Elena Ponomareva ${ }^{1,2, *}$, Vadim Grigoriev ${ }^{1,3}$, Marina Sorokina ${ }^{1,3}$, Angelika Kovaleva ${ }^{1}$, Peter \\ Geraskin $^{3}$, and Dinara Tazhbaeva ${ }^{1}$ \\ ${ }^{1}$ The Southern Scientific Centre of Russian Academy of Sciences, Chekhov ave., 41, Rostov-on-Don, \\ 344006, Russia \\ ${ }^{2}$ Don State Technical University, Gagarin sq. 1, Rostov-on-Don, 344003, Russia \\ ${ }^{3}$ Astrakhan State Technical University, Tatishchev St., 16, Astrakhan, 414056, Russia
}

\begin{abstract}
The article provides data on the use of a complex preparation, which includes sodium selenite and tocopherol (vitamin E) in the form of injections for sterlet breeders (Acipenser ruthenus Linnaeus, 1758). Obtained data confirm the ability of E-selenium to regulate metabolic processes towards the formation of reproductive tissue by optimizing them. Positive dynamics is manifested during the gametogenesis, in particular, the number of individuals with reproductive cells at the IV stage of maturity is increased.
\end{abstract}

\section{Introduction}

The study of the importance of vitamins and microelements in metabolism of fish is the subject of close attention of foreign and domestic researchers in aquaculture [1-5].

Special attention in estimation of the influence these elements is focused on studying the effect of biologically active substances on the reproductive function of fish which largely depends on ensuring the need for these compounds and their positive effect on metabolism [6-9].

Biologically active substances, exactly antioxidants, use for a long time in fish farming to improve the physiological state of fish under the negative influence of environmental factors. In recent years, there has been a significant increase in scientific research on antioxidant agents and their potential protective properties [10-13]. Vitamin E and selenium play a significant role among them.

Selenium takes part in the regulation of lipid peroxidation and in the antioxidant system of the body helping to protect the cell from the damaging effects of peroxides. This element is part of glutathione peroxidase which neutralizes pyroxidases arising during autooxidation of fats [14-16]. Selenium compounds can protect the organism from the toxic effects of heavy metals [17].

\footnotetext{
* Corresponding author : sor-marina@yandex.ru
} 
For fish rich in unsaturated, easily oxidized fatty acids, the presence in the body of a sufficient amount of substances involved in antioxidant protection is extremely important. Selenium deficiency causes loss of appetite in fish, inhibition of movement, depression of growth, and increased mortality. Muscular dystrophy, fatty liver degeneration, accumulation of fluid in the abdominal cavity, hemolysis of erythrocytes, and a decrease in hematocrit are found in fish that indicates a weakening and depletion of the antioxidant system [6].

Vitamin $\mathrm{E}$ is the most active natural fat-soluble antioxidant. It is a universal protector of cells membrane from oxidant damage, protecting biomembranes from their peroxide destruction. It is able to stabilize the mitochondrial membrane and save oxygen consumption by cells. Tocopherols are capable of exerting a positive biological effect by regulating gene expression, signal transduction, and modulation of cellular functions through protein-membrane interactions. Compared to other homologues of tocopherol $(\beta, \delta$ and $\gamma$ ), $\alpha$-tocopherol has the highest biological activity. The bioavailability of various forms of tocopherol is determined by their ability to bind to specific transforming proteins [18, 19].

Deficiency of vitamin E leads to disruption of the integrity of cell membranes, causes degenerative and dystrophic changes in muscles, nerve cells, liver cells, increases the permeability and fragility of capillaries, reduces the resistance of erythrocytes, disrupts the integrity of germ cells, which negatively affects the reproductive function [6].

The main source of vitamin $\mathrm{E}$ and selenium intake in the fish organism is food. N.A. Pudovkhin with co-authors [20] in their researches has established that concentration of selenium in predator fish organism is higher than in omnivorous fish. It was also noted that when selenium-containing preparations are included in the diet of fish, the amount of this microelement in the organs and tissues of the body increases in a dose-dependent manner. In addition, it was determined that in freshwater fish the highest concentration of selenium is observed in the liver - the main organ that performs the protein-synthesizing and detoxifying function - that is, the liver is a selenium depot. Also, accumulation of selenium occurs in the branchial lobes and gonads.

Excess selenium is most often excreted in fish through the gills and in the urine which makes it possible to speak of the absence of a gradual accumulation of this element with subsequent toxic effects on the body (accumulation effect) [6]. However, when fish are raised in a closed water ecosystem, there is a possibility that this ecosystem will be polluted when selenium is removed from the body. Therefore, it is very important to take into account the dosage and duration of the preparation selenium using in closed systems. It was found that selenium, as well as $\alpha$-tocopherol, has a connection with lipoproteins, especially with $\alpha-, \beta$ - fractions. It inhibits the formation of peroxides, it is necessary for protein biosynthesis on ribosomes, maintenance of membrane function, etc. [21]. Herewith there is a decrease in albumin and an increase in beta and gamma globulins that leading to an increase in the total amount of protein in the blood.

According to literature data [6] fish require selenium in amount of 0.15 to $0.50 \mathrm{mg} / \mathrm{kg}$ of feed to maintain normal physiological state. The level of selenium supply to the fish organism can be determined by the activity of the enzyme glutathione peroxidase. The maximum activity of glutathione peroxidase was recorded in trout plasma at a dietary selenium concentration of $1.38 \mathrm{mg} / \mathrm{kg}$ of feed.

The vitamin E requirements of fish depend on the amount of fat in the feed, especially the degree of its saturation. A large amount of polyunsaturated fatty acids in the feed increases the requirements for vitamin $\mathrm{E}$ and selenium. Large fluctuations in vitamin $\mathrm{E}$ requirements from 20 to $500 \mathrm{mg} / \mathrm{kg}$ can be associated with the amount of fat and the content of bioantioxidants in feed. The requirement for vitamin E in salmon is $30 \mathrm{mg} / \mathrm{kg}$, trout $100-500 \mathrm{mg} / \mathrm{kg}$, carp $50-500 \mathrm{mg} / \mathrm{kg}$, and channel catfish $50 \mathrm{mg} / \mathrm{kg}$. It is recommended 
to introduce vitamin $\mathrm{E}$ at least $400 \mathrm{mg} / \mathrm{kg}$ for whitefish breeders in industrial conditions [6]. The most optimal rate for the introduction of tocopherol into the sturgeon compound feed is $50 \mathrm{mg} / \mathrm{kg}$ of feed [22].

The antioxidant effect of vitamin $\mathrm{E}$ is significantly enhanced when combined with selenium, it is explained by the synergism of their action, and that is, these components work together more effectively than separately. Tocopherols (vitamin E) inhibit the peroxidation of unsaturated fatty acids and, thus, inhibit the formation of peroxides, and selenium in the glutathione peroxidase composition destroys already formed compounds. The need for selenium increases with a deficiency of vitamin E. Various options for the ratio of vitamin $\mathrm{E}$ and selenium are able to neutralize the signs of selenium deficiency. For example, for trout, a high content of selenium in the form of sodium selenite $(0.9 \mathrm{mg} / \mathrm{kg})$ and a low content of vitamin E $(41 \mathrm{mg} / \mathrm{kg})$ in feed, for salmon with a low concentration of selenium $(0.1 \mathrm{mg} / \mathrm{kg})$ and high concentration of vitamin $\mathrm{E}$ in feed $(500 \mathrm{mg} / \mathrm{kg})$, for channel catfish these ratios in feed correspond to $0.25 \mathrm{mg} / \mathrm{kg}$ of selenium and $30 \mathrm{mg} / \mathrm{kg}$ of vitamin E. These norms were sufficient to meet the needs for growth and development and high activity of glutathioperoxidase in these fish species. There is a definite relationship between selenium, tocopherol and sulfur-containing amino acids. Lack of tocopherol and selenium inhibits the conversion of methionine to cystine, and cystine becomes an essential amino acid [6].

Previously, we conducted researches on fry of hybrid Acipenser gueldenstaedtii Brandt, $1833 \times$ Acipenser baerii Brandt, 1869 to study the effect of the E-selenium preparation on the growth rate, mass accumulation, and the physiological state of the fish organism. As a result, a positive effect of the feed containing the E-selenium additive was revealed, expressed in an increase in the rate of linear growth and mass accumulation of experimental fry of hybrid in comparison with control individuals. In addition, the activation of lipid metabolism of the studied fish in the experimental variant was noted [23]. Studies carried out on sturgeon fish breeders have revealed the feasibility of introducing the preparate Eselenium to improve the physiological status and regulation of the reproductive function of sturgeon breeders [24].

The purpose of the research was to identify changes in the functional state of sterlet breeders and the development of their reproductive system when adjusting the dosage of the preparation of E-selenium and determining its effectiveness.

\section{Material and research methods}

Studies on the control of generative exchange of sturgeon breeders were carried out in the aquacomplex of the Coastal Scientific Expeditionary Base "Kagalnik" (Rostov Region, Kagalnik settlement). The objects of researches were sterlet breeders (Acipenser ruthenus Linnaeus, 1758). Experimental fish were kept in installation with a closed water supply with constant thermal $\left(19.5-21.5^{\circ} \mathrm{C}\right.$ ) and hydrochemical (oxygen saturation of water - 70$85 \%, \mathrm{pH}-7.6-8.1$ ) regimes. Feeding was with Coppens staple food. Feeding was carried out with artificial feed according to the calculated norms [25].

A complex vitamin preparation E-selenium containing in $1 \mathrm{ml}$ of selenium in the form of sodium selenite $-0.5 \mathrm{mg}$ and vitamin $\mathrm{E}-50 \mathrm{mg}$ was used for injection. The dosage of the preparation was chosen based on the biological needs of fish for selenium $(0.15-0.50$ $\mathrm{mg} / \mathrm{kg}$ ) and vitamin $\mathrm{E}(20.0-100.0 \mathrm{mg} / \mathrm{kg})$. The fish were injected intramuscularly 5 times with a frequency of 10 days with a dosage of $0.12 \mathrm{ml}$ of E-selenium per $1 \mathrm{~kg}$ of fish weight, the dose of the drug components per fish was $0.12 \mathrm{mg}$ of sodium selenite and $12 \mathrm{mg}$ of vitamin E. Individuals in the control variant were not injected with the vitamin complex.

Determination of the stages of fish maturity was carried out by ultrasound examination (US) using a Sono Scape scanner. 
To study the effect of E-selenium on the organism of sterlet breeders, hematological parameters were assessed: erythrocyte sedimentation rate (ESR), the concentration of hemoglobin, total serum protein, cholesterol, triglycerides and $\beta$-lipoproteins. Blood for analysis was taken from the tail vein (vena caudalis) using a $5 \mathrm{ml}$ medical syringe.

Erythrocyte sedimentation rate (ESR) was estimated by method of Panchenkov with use a device PR-3. When determining the concentration of hemoglobin in the blood a set of reagents from PLIVA - Lachema was used. The concentration of whey protein was determined using an IRF-454B2M refractometer. The determination of $\beta$-lipoproteins was carried out by the turbidimetric method according to Burstein and Samaille, based on the ability of $\beta$-lipoproteins to form an insoluble complex with heparin and calcium chloride; total cholesterol and triglycerides in the blood - by an enzymatic colorimetric method with the Cholesterol-Olglycerides and Tri-Glycerides diagnostic kits. Olvex "[25].

The results of the experiments were processed using the generally accepted methods of biological statistics and the Microsoft Excel program.

\section{Results and discussion}

When determining the degree of development of reproductive organs in the studied fish, it was found that at the beginning of the experiment $46.7 \%$ of females in the experiment and $30 \%$ in the control were at the II stage of gonad maturity. When injections were carried out to sterlet breeders kept in closed water supply conditions, an increase in the number of individuals whose generative tissue was at the IV stage of maturity was recorded from 26.7 $\%$ to $33.3 \%$, that is, by $6.6 \%$ (fig. 1 ). At the same time, the part of breeders with stage II of gonad maturity (GMS) decreased by $9 \%$, with III GMS - not significantly, but still increased - by $2.4 \%$. In the control variant, the number of fish with IV GMS, according to the results of the experiment, increased slightly by $0.3 \%$, III GMS by $2.5 \%$. The polarization coefficient of the oocyte nucleus of females in the IV SGM was on average $0.15-0.17$, that characterizes them according to the classification of M.S. Chebanov, E.V. Galich [26] as "close to maturation" and "capable of maturation".

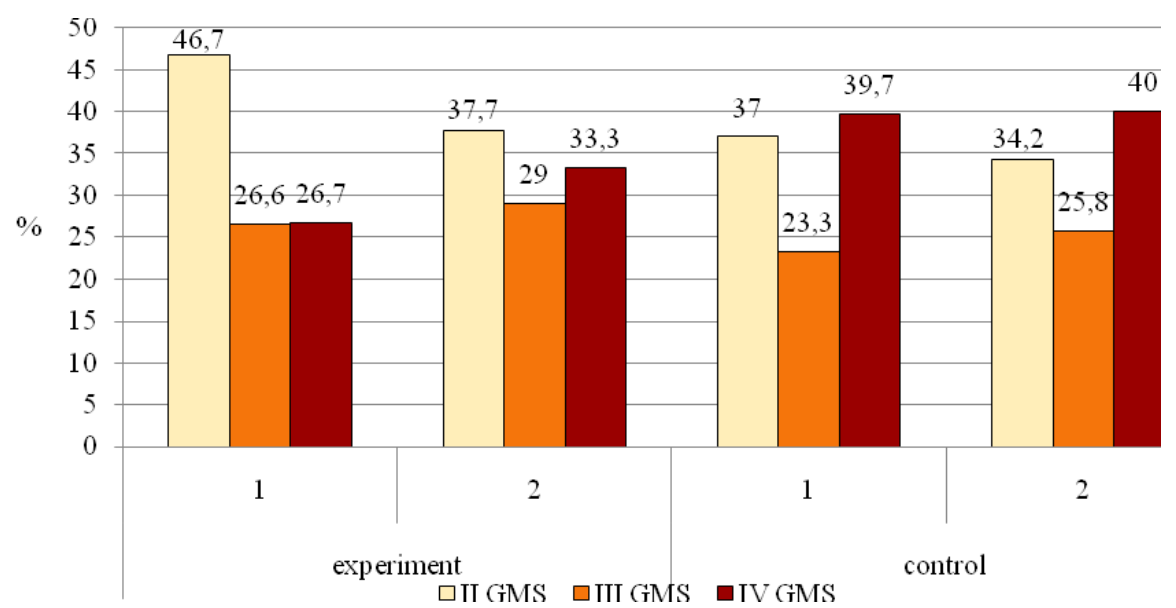

Fig. 1. The percentage of fish at different stages of gonad maturity (GMS): 1 - the beginning of the experiment, 2 - the end of the experiment.

It was noted that the fish mass indices remained practically unchanged with the development of the gonads. But, it should be noted that our early studies testified to the opposite (recorded an increase in the mass of producers in the experimental variant by 4.4 
$\%$, while in the control the mass increased by only $1.7 \%$ ). This circumstance is most likely due to the fact that the energy potential of the fish organism, as well as protein and lipid metabolism, upon entering the organs and tissues of the E-selenium complex was directed to the activity of the reproductive function and the formation of gonads.

One of the criteria for the physiological state of the body is hematological parameters.

In the study of the functional state of the experimental fish, a blood test was performed for ESR (erythrocyte sedimentation rate), the concentration of hemoglobin, total protein in the blood serum, as well as lipids - cholesterol, triglycerides and $\beta$-lipoproteins.

The ESR value changed slightly over the experiment period, but, in general, was within the normal range: at the beginning of the experiment in the experiment and in the control it averaged 3.4 and $2.15 \mathrm{~mm} / \mathrm{h}$ (Table 1 ).

By the end of the experiment, the ESR indicator in the experiment decreased by an average of $4.4 \%(3.25 \mathrm{~mm} / \mathrm{h})$, and in the control increased by $52.6 \%(3.27 \mathrm{~mm} / \mathrm{h})$, respectively.

Among the individual indicators in both variants, there were insignificant deviations from the norm (values of the indicator determined for sturgeon in natural conditions), which for sturgeon is $2.0-4.0 \mathrm{~mm} / \mathrm{h}$ [27].

Table 1. Hematological parameters of starlet.

\begin{tabular}{|l|c|c|c|c|}
\hline \multirow{2}{*}{ Parameters } & \multicolumn{2}{|c|}{ The beginning of experiment } & \multicolumn{2}{c|}{ The end of experiment } \\
\cline { 2 - 5 } & experiment & control & experiment & control \\
\hline ESR. mm/h & $3.4 \pm 0.55$ & $2.15 \pm 0.43$ & $3.25 \pm 0.55$ & $3.28 \pm 0.39$ \\
\hline Hemoglobin. g/l & $87.4 \pm 4.37$ & $78.2 \pm 7.10$ & $80.4 \pm 5.5$ & $81.78 \pm 2.31$ \\
\hline Total protein. g/l & $34.66 \pm 3.27$ & $30.54 \pm 3.78$ & $35.6 \pm 3.09$ & $38.23 \pm 3.98$ \\
\hline
\end{tabular}

The hemoglobin level in the blood of fish that received E-selenium injections decreased by $8 \%$ by the end of the experiment, and increased by $4.6 \%$ in the control. In general, there was a high level of hemoglobin in both variants, corresponding to the upper limit of the norm, which is in the range of 50-80 g/1 [27]. Since hemoglobin and ESR are indicators of oxidative metabolism and the presence-absence of inflammatory processes in the body, it can be assumed that in the presence of E-selenium, positive dynamics of these processes was recorded.

It was noted that the concentration of total protein in the blood serum of both groups of fish increased over the period of the experiment, but did not go beyond the accepted norm (for sturgeons under natural conditions, 28-40 g/l), but in the experiment this increase was small (by $2.7 \%$ ), while in the control - by $25.2 \%$. This indicates that the metabolic processes of fish with the addition of E-selenium are directed towards the formation of generative tissue, and more efficient utilization of feed components in the experimental group. The high level of whey protein in the control is likely due to the stress state of breeders [28].

Decrease in the concentration of triglycerides, cholesterol and $\beta$-lipoproteins were recorded in lipid metabolism (Figure 2). 


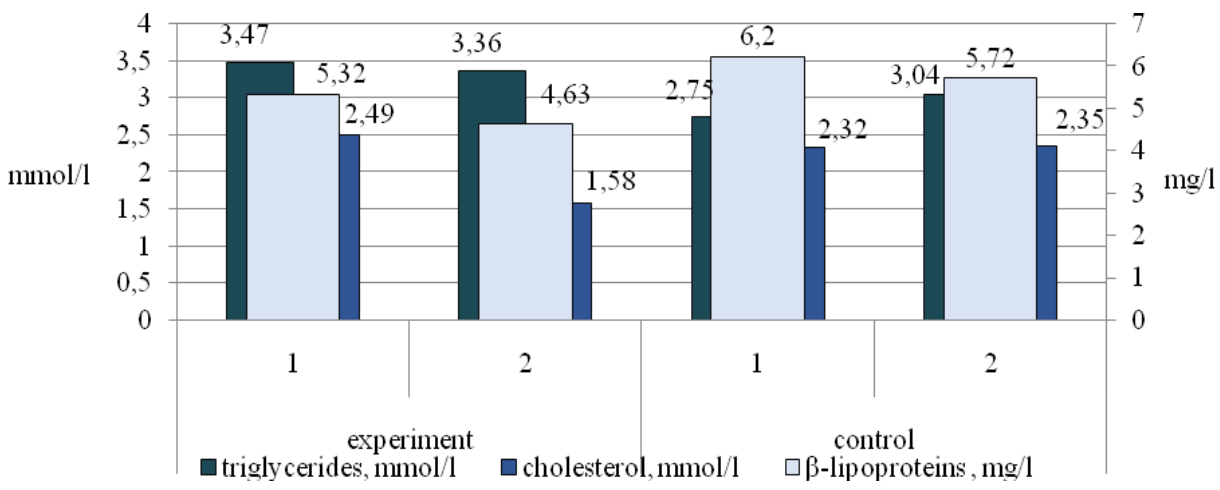

Fig. 2. The concentration of lipids in the blood of sterlet breeders: 1 - the beginning of the experiment, 2 - the end of the experiment.

Since cholesterol is associated with the synthesis of corticosteroid hormones, an increase in the amount of which occurs when an object is under stress, a $36 \%$ decrease in cholesterol level in the experimental version may indicate the protective effect of $\mathrm{E}$ selenium in the presence of unfavorable environmental factors. The level of triglycerides during the period of experiments in the experiment decreased by $3.2 \%, \beta$-lipoproteins - by $13 \%$. Triglycerides increased by $9.5 \%$ and $\beta$-lipoproteins decreased by $7.7 \%$ in the control. This phenomenon is observed at the end of the process of gonad formation and full maturation of the breeders. Other functional indicators changed insignificantly.

In general, the results of studies aimed at controlling the generative metabolism of sturgeons have confirmed the ability of a complex preparation of selenite $\mathrm{Na}$ and tocopherol (vitamin E) at a dose of $0.12 \mathrm{ml}$ per $1 \mathrm{~kg}$ of fish weight to regulate metabolic processes towards the formation of reproductive tissue at the expense of the body's energy reserves of fish.

Thus, the effect of a complex preparation, which includes sodium selenite and tocopherol (vitamin E), used in the form of injections to sterlet breeders (Acipenser ruthenus Linnaeus, 1758) to normalize the process of generative metabolism when grown in artificial conditions has been confirmed.

It was found that when using E-selenium, positive dynamics in the course of gametogenesis is manifested, in particular, the number of individuals whose reproductive cells are at the IV stage of maturity increases by $6.6 \%$. The effect of increasing the intensity of generative metabolism was revealed in experimental fish, the functional state of which corresponds to more mature females, in comparison with control ones.

\section{Acknowledgements}

The publication was prepared as part of the implementation of the SA of the SSC RAS, no. 01201354245 using the USI "MUC " of the SSC RAS and the Bioresource collection of rare and endangered fish species of the SSC RAS No. 73602.

\section{References}

1. I. Ilham, R. Fotedar, Animal Feed Science and Technology 217, 76-86 (2016) DOI: 10.1016/j.anifeedsci.2016.04.009 
2. A.A. Vasiliev, A.R. Khairova, Science and modernity-2017. collection of materials of the LI International Scientific and Practical Conference, 115-118 (2017)

3. E. Chahardeh Baladehi, S.A.A. Hedayati, Iranian Journal of Fisheries Sciences 17(1), 162-169 (2017)

4. A.R. Lozano, P. Borges, L. Robaina et al., Aquaculture 468(1), 175-183 (2017) doi.org/10.1016/j.aquaculture.2016.10.006

5. A.A. Bakhareva, A.D. Zhandalgarova, Yu.N. Grozescu et al., Izvestia of the Samara Scientific Center of the Russian Academy of Sciences 21(2-2(88), 169-174 (2019)

6. I. N. Ostroumova, Biological bases of fish feeding (GosNIORKh, SPB, 2012)

7. M.B. Furmanevych, Scientific Bulletin of Lviv National University of Veterinary Medicine and Biotechnology named after SZ Gzhytsky 18(65), 160-164 (2016)

8. S. Ghiasi, B. Falahatkar, M. Arslan, K. Dabrowski, Animal Reproduction Science 178, 23-30 (2017) doi.org/10.1016/j.anireprosci.2017.01.005

9. I. Fernández, J.M.O. Fernandes, V.P. Roberto, et al., Biochim et Biophysica Acta (BBA) General Subjects 1863(1), 39-51 (2019) doi.org/10.1016/j.bbagen.2018.09.017

10. O.A. Levina, Technological methods of increasing the efficiency of commercial sturgeon farming: author's ref. dis. ... cand. Agricultural Sciences: 06.02.10 (AGTU FGBOU Publishing House, Astrakhan, 2017)

11. Z. Selamoglu, Journal of Survey in Fisheries Sciences 4(2), 1-4 (2018) DOI: $10.18331 /$ SFS2018.4.2.1

12. P. A.J. Prabhua, E. Holen, M. Espe et al., Aquaculture 526, 2-14 (2020) doi.org/10.1016/j.aquaculture.2020.735413

13. S. Fontagné-Dicharry, V. Véron, L. Larroquet et al., Aquaculture 529, 735684 (2020) doi.org/10.1016/j.aquaculture.2020.735684

14. X. Li, D. Yin, J. Yin, Q. Chen, R., Food Chem Toxicol 72, 169-77 (2014) doi: 10.1016/j.fct.2014.07.023

15. R. Nastova, N. Gjorgovska, V. Kostov, Life Scientific Journal 3(1), 104-107 (2014)

16. K. Nazari, M. Shamsaie, N. Eila, A. Kamali, I. Sharifpour, Iranian Journal of Fisheries Sciences 16(1), 238-251 (2017)

17. I. Orun, Z.S. Talas, A. Alkan, Fresenius Environmental Bulletin 20, 104-108, (2012)

18. F. Shahidi, A. Costa de Camargo, Int. J. Mol. Sci. 17(10), 1745 (2016) doi:10.3390/ijms 17101745

19. V.A. Sargsyan, V.M. Kodentsova, V.V. Bessonov, A.A. Kochetkova, Nutrition issues 87(3), 5-11 (2018) DOI: 10.24411/0042-8833-2018-10025

20. N.A. Pudovkin, P.V. Smutnev, A. Yu. Kutepov, I.Yu. Kutepova, Bulletin of Veterinary Medicine 2(65), 53 - 56 (2013)

21. N.A. Pudovkin, A.Yu. Kutepov, Bulletin of the Saratov State Agrarian University. N.I. Vavilova 6, $39-41$ (2013)

22. A.A. Bakhareva, Scientifically grounded methods of increasing the productivity of sturgeon broodstock flocks by optimizing the technology of feeding and keeping in the conditions of fish farms in the Volga-Caspian basin: abstract of dis. ... Doctors of Agricultural Sciences: 06.02.08, 06.02.10 (Publishing house of FGBOU VPO "AGTU", Astrakhan, 2016)

23. G.F. Metallov, V.A. Grigoriev, A.V. Kovaleva et al., Bulletin of the Southern Scientific Center 9(2), 57-67 (2013)

24. G.F. Metallov, E.N. Ponomareva, M.N. Sorokin et al., Innovative solutions for 
increasing the efficiency of aquaculture: Materials of the All-Russian scientificpractical conference (All-Russia. exhibit. center, Moscow, 2019)

25. G.G. Matishov, E.N. Ponomareva, N.G. Zhuravleva et al., Practical aquaculture (Publishing house of the UNC RAS, Rostov n/A, 2011)

26. M.S. Chebanov, E.V. Galich, Guidelines for artificial reproduction of sturgeon: FAO Technical report on fisheries (2011) http://www.fao.org/3/a-i2144r.pdf

27. G.F. Metallov, E.N. Ponomareva, V.A. Grigoriev, et al., Series: fisheries 4, 117-131 (2018).

28. P.P. Geraskin The reaction of the body of the Caspian sturgeon (Acipenseridae) to environmental pollution: abstract of Ph.D. dis. ... doct. biol. Sciences: 03.03.01 (Publishing house of FGBOU VPO "AGTU", Astrakhan, 2013) 